Review

\title{
Inter-Individual Differences in Vicarious Tactile Perception: A View across the Lifespan in Typical and Atypical Populations
}

Helge Gillmeister ${ }^{1, *}$, Natalie Bowling ${ }^{2}$, Silvia Rigato ${ }^{1}$ and Michael J. Banissy $^{2}$

${ }^{1}$ Department of Psychology, University of Essex, Wivenhoe Park, Colchester, CO4 3SQ, UK

${ }^{2}$ Department of Psychology, Goldsmiths, University of London, New Cross, London, SE14 6NW, UK

Received 31 July 2016; accepted 1 December, 2016

* To whom correspondence should be addressed: E-mail: helge@essex.ac.uk 


\begin{abstract}
Touch is our most interpersonal sense, and so it stands to reason that we represent not only our own bodily experiences, but also those felt by others. This review will summarise brain and behavioural research on vicarious tactile perception (mirror touch). Specifically, we will focus on vicarious touch across the lifespan in typical and atypical groups, and will identify the knowledge gaps that are in urgent need of filling by examining what is known about how individuals differ within and between typical and atypical groups.
\end{abstract}

\title{
Keywords
}

Vicarious touch, mirror touch, synaesthesia, individual differences, somatosensory

\section{Introduction}

The tactile sensory modality represents information in personal space (i.e., on the body surface) and has garnered accelerated interest within multisensory and body-related research communities. To illustrate, the abstract book of the annual meeting of the International Multisensory Research Forum in 2005 (Rovereto, Italy) contained 159 instances of the words touch, tactile and somatosensory. Ten years later in 2015 (Pisa, Italy), there were 418 such instances.

Touch as a sensory modality (and its interaction with other senses, particularly vision) is so important in these research arenas because it provides a fundamental experience of our own body that is critical for the development and experience of one's sense of self (e.g., Blanke et al., 2015; Gallese and Sinigaglia, 2010; Legrand, 2006; Rochat and Striano, 2000). Intertwined with the experience of ourselves as agentive bodies, touch is also important in our everyday social interactions from birth through to old age. Social touch can affect the way we feel about and behave toward others (see Gallace and Spence, 2010). Non-human and human animal studies indicate that bodily contact forges positive affiliative bonds between two or more individuals (e.g., Boccia, 1986; Coelho et al., 1983; Light et al., 2005). 
Brain mechanisms involved in representing the first-hand experience of touch involve a number of subsystems depending on a) the type and location of tactile input and b) the function of tactile receptors. This input typically leads to neural activation within a set of brain regions: the somatosensory cortices. In recent decades a number of findings have suggested that the somatosensory cortices are not only involved in the first-hand experience of touch, but also the perception of touch to others (hereafter referred to as vicarious tactile perception or mirror touch; see Keysers et al., 2010 for review). Vicarious tactile perception has been linked to brain activation in a network of brain regions involved in the first-hand experience of touch (e.g., primary and secondary somatosensory cortices), sensorimotor processing (e.g., premotor and parietal cortices), and self-other distinction (e.g., superior temporal sulcus). In this regard, vicarious tactile perception in the brain is often referred to as being a consequence of a mirroring system for touch (or mirror-touch system) - a neural network that responds to touch applied both to the self and to others. Brain activation in the mirror-touch system has been reported to have a somatotopic arrangement (i.e., seeing touch to another person's face activates representations of one's own face) (e.g,. Keysers et al., 2004; Blakemore et al., 2005). Patterns of brain activation in the mirror-touch system have also been shown to vary within and between groups (for reviews of how vicarious perception has been shown to differ according to the presence of a variety of clinical and subclinical conditions see Lockwood, 2016; Ward and Banissy, 2015).

In this review, we will provide an overview of the evidence for, and the underlying mechanisms proposed to explain, vicarious touch in neurotypical adults and what is known about their inter-individual differences. This will be followed by a similar section dedicated to mirror-touch synaesthesia, one subclinical condition that has been associated with altered vicarious tactile perception in which the visual observation of touch leads to the conscious feeling of touch on the body. The third section will give an account of vicarious tactile 
perceptions from a developmental perspective, examining the evidence for vicarious touch in infants and older adults.

The aim of this review is to identify gaps in our knowledge and understanding of the mechanisms of vicarious touch, how they develop and how they differ in certain subgroups (e.g., synaesthetes) and between individuals within a population. We believe that the study of inter-individual differences is instrumental in delineating the mechanisms of vicarious touch. This is because the aspects of personality, sensorimotor aptitude, or social mindedness, along which individuals may differ from one another, may form the basis of what makes atypical groups (e.g., mirror-touch synaesthetes, depersonalised individuals) vary from the typical population. These inter-individual differences may have early developmental origins. Therefore, understanding individual differences in vicarious touch across the entire lifespan will help to explain the similarities as well as the differences between typical and atypical populations.

\section{Vicarious Touch in Neurotypical Adults}

There is copious evidence for the representation of other's touch in brain and behaviour. In the following, we give a brief overview of vicarious touch research over the past decade and examine the evidence for inter-individual differences in mirror touch in neurotypical adults.

The majority of what is known about vicarious touch comes from fMRI studies. In 2004, Keysers et al. first reported that the observation of another person's legs (or of blocks of wood) being stroked with a brush caused activations in the secondary somatosensory cortex (SII) of the observer, similar to activations in response to being brushed on their own legs. At a similar time, Blakemore et al. (2005) presented the first published case study of mirror-touch synaesthesia (see Section 3 below). Their group of non-synaesthetic control 
participants showed somatotopically organised activity in response to observed touch in the primary somatosensory cortex (SI), in addition to activity in the premotor and parietal cortices (fronto-parietal action mirroring network) and superior temporal sulcus (self-other distinction network). Since then, several fMRI studies have been published showing vicarious activations of the somatosensory cortices, both SI and SII, as well as associated activity in frontoparietal mirroring networks, self-other distinction networks, and insula (Cardini et al., 2011; Ebisch et al., 2008, 2011; Holle et al., 2013; Kuehn et al., 2013, 2014; Meyer et al., 2011; Nummenmaa et al., 2014; Schaefer et al., 2006, 2009, 2012, 2013; see Bufalari and Ionta, 2013; Keysers et al., 2010 for reviews; see also Lamm et al., 2015, for evidence of vicarious touch perception networks specific for pleasant touch and for unpleasant touch). Distinct neural indices of vicarious tactile perception have also been provided in EEG/ERP and MEG studies (e.g., Adler et al., 2016; Bufalari et al., 2007; Coll et al., 2015; Deschrijver et al., 2015; Lankinen et al., 2016; Martinez-Jauand et al., 2012; Pihko et al., 2010; Streltsova and McCleery, 2014).

Interestingly, one of the most recently published fMRI studies (Chan and Baker, 2015) found consistent activations of posterior parietal cortices (PPC) but not of SI or SII during touch observation. This led the authors to question the role of somatosensory cortices in favour of PPC. PPC contains visual-tactile multisensory neural populations coding for body-object interactions (see Chan and Baker, 2015) and shared body maps (e.g., Bolognini and Maravita, 2007; Ishida et al., 2010), and is the main source of visual inputs to the frontoparietal mirroring system (e.g., Keysers et al., 2010; Rizzolatti and Craighero, 2004).

More causal implications of both SI and PPC in vicarious touch have come from transcranial magnetic and direct-current stimulation (TMS/tDCS) studies (Bolognini et al., 2011a, b, 2013, 2014; Wood et al., 2010). For example, Bolognini et al. (2011) showed that rTMS over contralateral, but not ipsilateral, SI selectively impaired visual perceptions of a 
hand touching another hand, while rTMS over SII interfered with visual perception only in a non-touch-specific manner. After stimulating SI with paired-pulse TMS, Bolognini et al.'s (2014) participants misreported feeling touches on the hand contralateral to stimulation while viewing a similar hand being touched. This was found both when SI was primed intracortically and when it was primed via posterior parietal cortical stimulation. These TMS studies thus suggest that SI is causally involved in vicarious touch via links with posterior parietal cortex, which are activated by body-related visual inputs (Keysers et al., 2010).

It is thought that there are functional dissociations within SI, where earlier processing stages (in BA3) are confined to signals that originate on our own body (remain 'private', Keysers et al., 2010; but see Lankinen et al., 2016 for claims that this may differ for haptic touch), while later processing stages (in BA2, SII, and probably BA1) may include representations of other people's somatic experiences (see also Schaefer et al., 2012). This mirroring aspect of SI is considered to be part of a broader neural network responsible for mirroring (e.g., Avikainen et al., 2002; Keysers and Gazzola, 2009; Molenberghs et al., 2012; Molnar-Szakasc and Uddin, 2013; Pineda, 2005; Ruby and Decety, 2001) and emotion recognition (e.g., Adolphs et al., 2000; Wood et al., 2016).

Bufalari and Ionta (2013) suggested that the mirroring part of the SI has a twofold function in social interactions: it encodes the sensory qualities of one's own and others' bodily sensations via feedback from multisensory areas in the broader frontal-parietal network, and is further modulated by the attributed affective components of human tactile interactions on the basis of its links with insular cortex.

In line with this, the sensory qualities of observed touch do appear to affect the somatosensory response. In a behavioural study, the enhancement of felt tactile intensity during the visual observation of touch on another person's hand was found to be stronger for active than passive touch (Gillmeister, 2014). In another study, Meyer et al. (2011) showed 
that visual observation of touch can cause differential activity in SI depending on the object that was observed to be touched. SI activity has also been found to correlate with the rated intensity (Bufalari et al., 2007) and with the rated unpleasantness (Martinez-Jauand et al., 2012) of observed tactile sensations. In these studies, SI activity was measured electrophysiologically and indexed by early somatosensory evoked potentials (SEPs) induced by median nerve stimulation at around $50 \mathrm{~ms}$ post-stimulus onset. The SEP component around this time (variably called P50, P45 or P40) is thought to be generated in SI (e.g., Allison et al. 1989, 1992; Schubert et al., 2008), and has also been implicated in touch mirroring in other ERP studies using mechanical rather than electrical tactile stimulation (Adler et al., 2016; Deschrijver et al., 2015).

Interestingly, Martinez-Jauand et al.'s (2012) study reported that P50 amplitudes during touch observation were positively correlated with self-reported perspective-taking abilities, a cognitive empathy trait. Similarly, individual differences in perspective-taking have been found to correlate with hemodynamic S1 responses to observed touch (Schaefer et al., 2012) and action-related sounds (Gazzola et al., 2006): individuals with greater perspective-taking abilities had greater SI activations. Bolognini et al. (2014) reported that the effects of SI transcranial magnetic stimulation on behaviour correlated with reports of feeling touch from viewing it, as well as with both perspective-taking and empathic concern. Specifically, individuals who misreported feeling touches on the hand contralateral to stimulation while viewing a similar hand being touched also felt better able to put themselves into others' shoes, and reported to have more sympathy and concern for others. Greater perspective-taking was further associated with greater impairments in encoding the affective valence of others' bodily states resulting from disruption of S1 activity (Bolognini et al., 2013b). 
Perspective-taking is one of the cognitive empathy subscales of the Interpersonal Reactivity Index (IRI, Davis, 1983). This subscale measures the extent to which respondents take other people's mental perspective through seven statements such as "I sometimes try to understand my friends better by imagining how things look from their perspective" and "If I'm sure I'm right about something, I don't waste much time listening to other people's arguments", which are scored on a Likert scale according to how well it describes the respondent. Empathic concern is an emotional or affective empathy IRI subscale probed through statement such as "I often have tender, concerned feelings for people less fortunate than me" and "Sometimes I don't feel sorry for other people when they are having problems". It is more typically linked to the individual variation in the degree of activation within brain networks involved in the observation of painful touch (e.g., Avenanti et al., 2005; Singer et al., 2004).

In addition to these inconsistencies, it is also noteworthy that no relationships have been reported between indices of vicarious touch and other cognitive IRI subscales (fantasy), other affective / emotional IRI subscales (personal distress), or between vicarious touch and other tools that measure trait empathy (e.g., Empathy Quotient, Baron-Cohen and Wheelwright, 2004; Emotional Contagion Scale, Doherty, 1997 — although fewer studies have tended to employ these specific measures). In this regard it is of interest that Lamm et al.'s (2011) meta-analysis of empathy for pain found that state empathy measures (e.g., trial by trial affective ratings) predict empathic cortical activations more sensitively than trait measures (e.g., questionnaires like IRI). This strongly indicates that the study of empathyrelated inter-individual differences in mirror touch would benefit from employing experimental designs that probe state empathy.

The affective meaning conveyed by interactive bodily touch has been shown to increase S1, S2, and insular activity (Bjornsdotter and Olausson, 2011; Kress et al., 2011). 
Observing human-based intentional touch causes stronger S1 activations (Ebisch et al., 2008; Kress et al., 2011) and engages tactile mirroring processes to a larger extent (Deschrijver et al., 2015; Holle et al., 2011; Streltsova and McCleery, 2014), compared to object-based nonintentional touch. These S1 activations are said to play a key role in understanding the affective consequences (Bolognini et al., 2013b) of tactile interactions between people (Rossetti et al., 2012). While the observation of facial touch on another person generally facilitates tactile detection on the face (Serino et al., 2008, 2009; Vandenbroucke et al., 2015), this facilitation is measurably increased when observing persons we feel a greater affiliation with (Serino et al., 2009; see also Fini et al., 2013). Interestingly, the strongest enhancement of tactile detection is in fact seen when observing one's own face (Cardini et al., 2011s, 2013; Serino et al., 2008). In a recent study, somatosensory cortical activity was also found to be positively related to one's own self-reported levels of engagement with the haptic contents of a movie showing dynamic bodily interactions with surfaces (water, sand, rocks; Lankinen et al., 2016). This suggests that these affective modulations of SI may be more than reflecting interpersonal somatic experiences; they may be driven by how well we can, and perhaps are willing to, resonate with the viewed touch. Resonance is likely to increase the more self-related a viewed bodily experience is.

It is thought that affective SI modulations are based on its links with insular cortex (e.g., Bufalari and Ionta, 2013), which is involved in various aspects of self-awareness (see e.g., Blanke et al., 2015) and also has mirroring properties (e.g., Keysers et al., 2010). In addition to somatosensory activation, pleasant touch on the arm elicits similar responses in the posterior insula during the personal experience and the observation of somebody else's arm being stroked (Bjornsdotter and Olausson, 2011; Ebisch et al., 2011; see also Schaefer et al., 2012, for evidence of mid-insular activity). The anterior insula specifically has been 
implicated in mirror-touch synaesthesia (Blakemore et al., 2005) and in empathy for pain (Lamm et al., 2011).

Interestingly, both SI and posterior insula activity are sensitive to whether the touched body part is seen from a first- or third-person perspective (Ebisch et al., 2011; Schaefer et al., 2009). Behaviourally, visual-spatial perspective has typically been shown to affect tactile detection only when painful touch is observed (Bach et al., 2014; Vandenbroucke et al., 2015). However, Banissy and Ward (2007) have reported a greater impact of viewed touch from a first-person relative to third-person perspective on visual-tactile congruency effects (see Section 3 below) in mirror-touch synaesthetes and typical adult controls. These findings suggest that both SI and insula may encode the source of tactile sensation (self vs. other; or more broadly self vs. non-self, see also Section 3) and thus play a role in mediating body ownership. In line with this, posterior insula lesions are associated with heautoscopy (Heydrich and Blanke, 2013). In heautoscopy a second own body is perceived and strongly identified with, such that some patients can feel present in two locations at the same time.

SI is also thought to be a critical component in the sense of body ownership (Aspell, Palluel, and Blanke, 2012; Otsuru et al., 2014). These studies measured systematic changes in SI activations during the experience of body ownership of a fake hand or back using variations of the rubber hand illusion (RHI). The RHI is an illusion of body ownership in which seeing touch to an inanimate hand that occurs in synchrony with first-hand touch to the participants' own hand can lead to a greater sense of body ownership towards the inanimate hand (Botvinick and Cohen, 1998).

In line with this, a recent study from our lab has implicated SI in vicarious tactile representations during self-face observation in healthy adults (Adler et al., 2016; see also Cardini et al., 2011 for related findings). Importantly, we found that the P45 index of vicarious touch was not observable in individuals who feel less connected with their bodily 
self (high levels of depersonalisation). Depersonalisation is a psychological condition characterised by estrangement, detachment or disconnection from one's own being (e.g., Simeon, 2004), and in its mild form it has a high life-time prevalence (up to $80 \%$, e.g., Hunter, Sierra, and David, 2004). Interestingly, individuals with higher levels of depersonalisation are also reported to have higher levels of body ownership illusions (Kanayama et al., 2009; see also Sierra et al., 2002), in which SI has been implicated (e.g., Aspell et al., 2012; Otsuru et al., 2014). This further supports the suggestion that the (altered) sense of bodily self is associated with (atypical) SI activity.

The involvement of the insular pathway to SI may be of particular interest in these phenomena. This is because insula activation is classically associated with interoceptive awareness (anterior insula: Ernst et al., 2012; posterior insula: Kuehn et al.2016). Interoceptive awareness is the ability to perceive and regulate one's attention to bodily signals (e.g., Mehling et al., 2012). Aspects of interoceptive awareness are in turn negatively correlated with feelings of dissociation from one's bodily self (Mehling et al., 2012), which has been shown to reduce vicarious touch responses at SI stages of processing (Adler et al., 2016).

A stronger sense of bodily self also entails a stronger sense of the difference between self and non-self sources of stimulation. This may be because incoming tactile information can be better mapped to existing models of self-related bodily experiences (e.g., Tsakiris et al., 2011), processes in which the insula is critically involved (Critchley et al., 2004). Accordingly, the RHI, which relies on a blurring of self-other boundaries through synchronous visual-tactile stimulation, is stronger in individuals with a more malleable sense of self: within neurotypicals (Tsakiris et al., 2011), within anorexic individuals and between anorexic and healthy control groups (Eshkevari et al., 2012; see also Mussap and Salton, 2006), between neurotypical groups with low and high levels of depersonalisation 
(Kanayama et al., 2009), and between schizophrenic and healthy control groups (e.g., Thakkar et al., 2011). More directly related to vicarious sensations, Adler et al. (2016) showed reduced differences between later-stage SEP indices of vicarious touch (P200) during self-face and other-face observation in individuals with high levels of depersonalisation. Also, Bird et al. (2010) found weaker vicarious pain responses in the anterior insula of autistic and control individuals with higher levels of alexithymia, which is also related to interoceptive deficits and low trait empathy.

Altogether, this suggests that the study of interoceptive awareness and its multiple dimensions, and the associated processes of distinguishing self and non-self sources of stimulation, may provide a rich ground for understanding inter-individual differences in vicarious touch perception.

\section{Conscious Vicarious Tactile Experiences in Mirror-Touch Synaesthesia}

While the majority of people do not experience a conscious sensation of touch on their own body from pure observation, for those with mirror-touch synaesthesia (MTS), a first-hand tactile sensation is experienced (Ward and Banissy, 2015). The prevalence of MTS is estimated at 1.6\%; however, self-reported prevalence is much higher, at around $10.8 \%$ (Banissy et al., 2009a). The $1.6 \%$ estimate comes from participants that objectively differ to control participants on behavioural tests designed to verify the presence of MTS, and therefore this conservative estimate and approach is considered best practice for studies on MTS. A prevalence of $1.6 \%$ also relates to the proportion of individuals that experience conscious response to observed touch to humans, but it is of note that some individuals also report vicarious touch in response to inanimate stimuli (such as objects or dummy body parts) (Banissy and Ward, 2007; Banissy et al., 2009a; Holle et al., 2011). 
In terms of authenticity, MTS has most commonly been authenticated behaviourally using a visual-tactile congruity task developed by Banissy and Ward (2007), in which participants report the location of a tactile stimulus, while observing another person (or object) being touched. Observed touch can either be spatially congruent or incongruent with the self-reported location of synaesthetic induced touch (i.e., the location where an individual reporting MTS claims to experience a sensation when observing touch). Compared with controls, MTS participants typically make more errors and show a greater congruency effect in their responses. This indicates that the observed touch generates a tactile sensation on the synaesthete's body that feels similar to first-hand tactile experience, leading to greater interference. This pattern of behaviour (i.e., greater interference on the visual-tactile congruity task) is also seen in a manner that is consistent with intra-individual differences within the MTS group.For instance, Banissy and Ward (2007) identify two contrasting spatial reference frames for vicarious tactile sensations in MTS: a) anatomical (e.g., when observing another person being touched on the left cheek, the synaesthete reports a sensation of touch on their own left cheek) and b) mirrored (e.g., when observing another person being touched on the left cheek, touch is reported on the right cheek, mapping to the same side of the body as if looking in a mirror). That is to say that an individual with a mirrored MTS shows congruency effects under a mirrored frame of reference, whereas an individual with an anatomical MTS shows congruency effects under an anatomical frame of reference (see also White \& Davies, 2012).

Complementing behavioural differences, functional MRI studies have shown that, compared with controls, MTS participants display greater activation of both primary (SI) and secondary (SII) somatosensory cortex during the observation of touch (Blakemore et al., 2005; Holle et al., 2013) and that this can match a pattern that would be expected given their self-reported frame of reference (e.g., mirrored frame of reference; Holle et al., 2013). In this 
regard, individuals with MTS show greater activation in the same regions involved in mirroring touch in typical adults. In addition, MTS participants show increased grey matter density in SII than controls (Holle et al., 2013). These observations have contributed to the development of Threshold Theory, which assumes that hyperactivity of tactile mirror systems underlies conscious vicarious experience in MTS (Blakemore et al., 2005; see Ward and Banissy, 2015 for review). In support of Threshold Theory, congruency effects akin to those found in MTS on the visual-tactile congruity task described above have been induced in controls by increasing excitability in somatosensory cortex with transcranial direct-current stimulation (tDCS; Bolognini et al., 2013a).

While evidence from fMRI and tDCS studies points to a hyperactive mirror system for touch in MTS (Blakemore et al., 2005; Bolognini et al., 2013a; Holle et al., 2013), the cause of this increased activity remains unclear. Furthermore, a somatosensory hyperactivity account cannot explain additional structural brain differences observed in MTS, such as reduced grey matter density in medial prefrontal cortex (mPFC) and the right temporoparietal junction (rTPJ; Holle et al., 2013). The more recent Self-Other Theory (Banissy and Ward, 2013; Ward and Banissy, 2015) has been proposed to account for some of these factors. Broadly, Self-Other Theory suggests that vicarious experiences in MTS are related to atypical abilities in distinguishing the self from others (or more broadly in distinguishing 'me from not me' in the case of objects). One mechanism by which this is thought to occur is through an extension of bodily self-awareness, with MTS being linked to a more expansive plasticity of the bodily self (Banissy et al., 2009a; Banissy and Ward, 2013; see also Tamir \& Mitchell, 2010). In line with this, individuals with MTS experience the rubber hand illusion (RHI; see Section 2) and enfacement illusion (Tsakiris, 2008) without any tactile stimulation (Aimola Davies and White, 2013; Maister et al., 2013). Importantly, for non-synaesthetes, the RHI requires visual and tactile congruency (i.e., tactile stimulation of the participants' 
own hand, while viewing synchronous touch on the dummy), but for MTS participants simply seeing touch to the dummy hand can lead to an atypical sense of ownership (Aimola Davies and White, 2013).

In addition to body-ownership, Cioffi et al. (2016) have demonstrated that MTS is associated with a greater sense of vicarious agency. In that study, participants were tested on a vicarious agency task in which they saw hand actions performed in a mirror placed in front of them while listening to action instructions that matched or mismatched with the actions performed. While the actions in the mirror appeared to the participant in a congruent location with where they would expect to see actions performed by their own body, the seen actions were actually performed by an experimenter (i.e., another person) while the participants were at rest (thereby inducing blurred boundaries between the self and other). Participants with MTS showed higher judgments of agency (relative to typical adult controls) over the experimenter's movements in the match condition. MTS participants also showed a stronger sense of ownership towards the experimenter's hand compared to controls, but importantly this was in both the match and mismatch conditions; suggesting that merely seeing another's body making an action in a location that corresponds to where one expects to see one's own body was sufficient for mirror-touch synaesthetes to treat other people's bodies as their own. Together with the findings on sense of ownership in MTS described above (also see Maister et al., 2013), this evidence indicates a greater susceptibility to self-other merging in MTS, which may contribute to altered patterns of vicarious response seen in this group.

Consistent with the notion that altered malleability of the self may contribute to mirror-touch synaesthesia, non-synaesthetes show greater levels of vicarious response to others that are perceived similar to themselves. For example, Adler et al. (2016) argued that vicarious touch as indexed by SEPs like P45 is stronger for touch that can be more easily (mis)attributed to the self. Indeed it may be suggested that SI activations in experimental 
studies of vicarious touch discussed in Section 2 reflect an amount of (mis)identification with a viewed body part (see Bach et al., 2014; Mahayana et al., 2014; Schaefer et al., 2006 for related arguments). This may be because these studies typically manipulate the viewed body part's location, orientation and/or felt experience of touch relative to the observer's own, hidden body part. Since the typically used body parts (e.g., hand, arm, leg or back) are less obviously one's own than the face, an identification with the viewed body part may occur at SI stages of sensory processing, not only when viewing one's own body, but also when the touched body part is a another person's (see Bufalari et al., 2007; Deschrijver et al., 2015; Martinez-Jauand et al., 2012; Schaefer et al., 2012).

Another important process that we tend to implement during vicarious perception is the ability to control the degree to which we privilege representations of the self or representations of other people. For example, in order to experience appropriate levels of vicarious response we must enhance the representations of others and inhibit the representation of one's own affective or sensory state; however in order to prevent excessive personal distress from another's negative state, it can be adaptive to inhibit the representation of the other's affective state and enhance the representations of the self. Interestingly, and consistent with Self-Other Theory, individuals with MTS have also been shown to have a difficulty with self-other control in situations that require inhibiting representations of others while boosting representations of the self. In the study by Santiesteban et al. (2015a), MTS participants showed impaired performance on an imitation-inhibition task requiring representations of the self to be enhanced, but representations of others to be inhibited; but comparable performance with controls on visual perspective-taking and theory of mind tasks which require enhancing representations of others while inhibiting the self (Santiesteban et al., 2015a). In this regard, it seems that even in the absence of conscious vicarious tactile experiences (i.e., no synaesthetic inducer), individuals with MTS show difficulties inhibiting 
others. This difference is not well accounted for by Threshold Theory, but is in line with predictions of Self-Other Theory that promote the hypothesis that atypical self-other abilities lead to altered vicarious response. Importantly, it also appears that in non-synaesthetes selfother control mechanisms play a key role in vicarious perception. For instance, De Guzman and colleagues (2016) show that training the ability to control self-other representations can modulate the degree of vicarious pain experienced towards to other people. Mechanisms of self-other control have also been implicated in modulating imitative responses driven by motor mirror systems (Brass, Ruby and Spengler, 2009; Hogeveen et al., 2015). With this collected evidence in mind, interactions between mechanisms involved in mirroring others' experience (as per Threshold Theory) and self-other distinction (as per Self-Other Theory) may manifest themselves as individual differences in vicarious perception.

\section{Vicarious Touch across the Lifespan}

Like most psychological and neuroscientific research, all of the previously discussed studies have involved young adults. We know little about vicarious touch in infants, young children, and older people. In this section we provide an overview of developmental studies of (vicarious) touch and related multi-sensory-motor processes to date.

The tactile sense is the first to develop in the womb and matures earlier than other sensory modalities (e.g., Atkinson and Braddick, 1982; Bernhardt, 1987). Developmental studies have shown that SEPs can be reliably detected in preterm infants from the $25^{\text {th }}$ week of gestation (Hrbek et al., 1973; Taylor et al., 1996) when their hand is stimulated. Reliable SEPs in response to vibrotactile stimuli in infants in the second half of their first year of life have also recently been shown (Rigato et al., 2014). In this study the strongest responses were recorded over somatosensory regions in the hemisphere contralateral to the stimulated hand, in line with another recent infant study (Saby et al., 2015). 
It is likely that vicarious tactile experiences develop alongside the representation of one's own tactile sensations. Developmental psychologists surmised that experiences like seeing and feeling your own body move provide the multi-sensory-motor contingencies that are instrumental in giving rise to bodily self-consciousness (e.g., Rochat and Striano, 2000; Zmyj et al., 2011).

Consistent with this assumption, recent studies have shown that sensitivity to the synchrony between seen and felt body-related stimuli may be present from birth (Filippetti et al., 2013, 2015; see also Addabbo et al., 2015). Filippetti et al. (2013) demonstrated that newborns prefer to look at an infant face being touched by a brush when a synchronous tactile stimulation is applied to their own face. Such effects are specific to upright faces only (vs. inverted; Filippetti et al., 2013), present for hand-to-hand touch but not object-to-hand touch (Addabbo et al., 2015), and stronger when touch is applied to a spatially congruent (vs. incongruent; Filippetti et al., 2015) location on the face. This suggests that newborns' preference for synchronous (vs. asynchronous) visual-tactile stimulation is relatively specific to stimuli that are more clearly related to their own bodies.

In a subsequent functional near-infrared spectroscopy (fNIRS) study, Filippetti et al. (2014) demonstrated that five-month-old infants also process visual-motor information related to the body. Using delayed vs. real-time video feedback of infants' own facial and upper body movement, they showed a significantly reduced cortical response when visualmotor stimuli were not presented in synchrony.

Further related to the study of shared bodily experiences is prior work examining infants' brain responses during action production and observation of another person performing an action with her hand, or her foot (Marshall et al., 2013; Saby et al., 2013). Those studies found that at 14 months of age, a somatotopic pattern of mu rhythm desynchronization — indicating an increase in sensorimotor cortical activity — was present 
during both action production and action observation. Moreover, mu desynchronisation was somatotopically organised, that is, larger over the somatosensory areas specific to hands or feet respectively (see also Marshall and Meltzoff, 2014). This was also true for the somatotopic response pattern recorded at 7 months of age as shown by the somatosensory evoked potential elicited by brief tactile stimulation of infants' hands and feet (Saby et al., 2015). These findings indicate that relatively sophisticated interconnections between the representations of the self and others' bodies are present shortly after the first year of life.

Magnetoencephalographical (MEG) techniques have also lent support for the notion of shared multi-sensory-motor body maps in early childhood. In a study by Remijn et al. (2014), three- to four-year-old children received touch stimulation to their index finger and at the same time watched a video of someone else being touched either at the index finger (congruent visuotactile information) or on the toe (incongruent visuotactile information). Over the contralateral somatosensory cortex, a middle-latency equivalent current dipole (ECD), occurring around $100 \mathrm{~ms}$ after stimulus onset, was modulated by the visual information so that it was higher for the congruent visuotactile information than for the incongruent visuotactile information or a tactile-only condition. This provides evidence that somatotopically organised interactions between visual and tactile information, which may originate very early in life (Filippetti et al., 2015), are clearly present in children.

During development in childhood and younger adulthood, functional enlargements of the topographically organised maps in somatosensory cortex are associated with learning and enhanced tactile performance as a result of strengthened connectivity (e.g., Elbert et al., 1995; Godde et al., 2000; Pascual-Leone and Torres, 1993; Ragert et al., 2004). Toward older adulthood, however, enlargements of the somatotopic maps are thought to reflect greater functional overlap between maps due to reduced intracortical inhibition (e.g., Kalisch et al., 2009). In line with this, old-age-related cortical reorganisation has been shown to be 
associated with decline in tactile acuity and sensorimotor coordination (e.g., Kalisch et al., 2009; Spengler et al., 1995).

It would stand to reason that the decline in tactile performance related to cortical reorganisations in late adulthood also entails a decline in vicarious tactile representations. We are not aware of any studies actually demonstrating this, however. There are no studies that show, for example, that the increasing functional overlap of somatotopic maps in SI extends to representing touch on another's body, or that tactile perceptual performance decreases both for self-related and for non-self-related stimuli.

A further question is whether the presumed decline in vicarious touch precedes or cooccurs with the decline of self-related tactile representations. Individual differences in agerelated decline of vicarious touch are also not known, but it may be speculated that those with relatively higher levels of intracortical inhibition would (have higher levels of vicarious touch and) be resistant for longer toward the decline in tactile acuity, sensorimotor coordination, as well as the accurate representation of another's somatosensory experiences.

Several other findings would also suggest a decline in vicarious tactile perceptions in older adulthood. For instance, reductions in vicarious perception have been associated with higher levels of alexithymia (e.g., Bird et al., 2010); alexithymia is associated with a difficulty identifying and labelling emotions from bodily cues (Bagby et al., 1994). Alexithymia has also been identified as a predictor of depersonalisation disorder (Simeon et al., 2009); which, as noted above, has been linked with modulations of vicarious tactile perception in younger adults (Adler et al., 2016). Interestingly, older adults tend to show greater self-reported alexithymia than younger adults (Lane et al.1998; Mattila et al., 2006; Paradiso et al., 2008). In this regard, one might predict that aging would be associated with declines in vicarious tactile perception (at least in those older adults that show greater selfreported alexithymia). This is an avenue that we are currently exploring. 
In addition to changes in alexithymia in later life, it has been widely reported that older adults also show impairments in other aspects of social perception that might point to declined vicarious perception. For example, older adults tend to show reductions in emotion perception (Ruffman et al., 2008), which can act as an important precursor to empathy (also see Yang and Banissy, 2016 for review). Indeed, self-reported trait cognitive empathy (as assessed by the Empathy Quotient; Baron-Cohen and Wheelwright, 2004) appears reduced for older compared with younger adults (Bailey et al., 2008). As described in Section 2, in young adult participants decreased self-reported cognitive empathy has repeatedly been linked with reduced brain activation in somatosensory areas during vicarious tactile perception (Bolognini et al., 2013a, 2014; Martinez-Jauand et al., 2012; Schaefer et al., 2012). With this in mind, if older adults recruit similar brain mechanisms, one might predict that vicarious somatosensory representations could decrease in later life.

\section{Summary and Conclusions}

In over a decade of research on vicarious touch, very few studies have looked explicitly at inter-individual differences. Overall, the evidence suggests that embodiment and self-other processes are important in determining the extent of vicarious tactile perception. The extent to which observed touch is embodied by the observer appears to depend on several factors: our prerequisite sense of bodily self (e.g., Adler et al., 2016) and how much we engage with the viewed touch (e.g., Lankinen et al., 2016). Our sense of self, as measured by our interoceptive awareness, our sense of body ownership, and our sense of agency, for example, is subject to large inter-individual differences (e.g., Tsakiris et al., 2011), and this looks to be a promising avenue for vicarious touch research. Indeed the sense of self has been shown to be altered in individuals that experience mirror-touch synaesthesia (e.g., Maister et al., 2013; 
Aimola-Davies and White, 2013; Cioffi et al., 2016), and this variability in the malleability of the self is considered to play a key role in contributing to the degree to which we experience conscious versus unconscious vicarious sensations (Ward and Banissy, 2015). The sense of self is also altered in a variety of atypical populations (e.g., alexithymic, depersonalised, eating disordered and schizophrenic individuals), in whom the vicarious representation of touch is understudied.

Vicarious somatosensory activity may also be modulated by inter-individual differences in cognitive and affective empathy (e.g., Bolognini et al. 2013a, 2014, Schaefer et al., 2012). While findings are not entirely consistent across studies, the most frequently reported relationship is between vicarious touch and the ability to cognitively represent the mental contents of another person's mind ('perspective-taking'). It is important to note that the perspective-taking skills measured with the IRI are more similar to mentalising skills (e.g., Rutherford, 2004) than to visual-spatial perspective taking, which has been used to elucidate self-other-related processing (e.g., Santiesteban et al., 2012, 2015a; see also Heyes, 2014; Santiesteban et al., 2015b). Future studies should clarify how these sets of skills are linked to one another and to vicarious tactile perception. Further, measuring empathy (and other personality aspects) in a situational manner (e.g., on a trial-by-trial basis) during touch observation may serve to uncover the relationships between personality and vicarious touch perception better than measuring self-reported traits.

Future studies should also investigate how vicarious touch relates to the five-factor model of personality (see Bufalari and Ionta, 2013, for a similar call). Individual five-factor traits are known to be associated both with individual empathic traits (e.g., Mooradian et al., 2011) and with SI activity in response to first-hand touch (Schaefer et al., 2012, 2013). While this would suggest that tactile mirroring mechanisms might be modulated by personality traits, to date, these two strands of research have not been combined. 
The evidence also strongly points to the necessity to test groups other than healthy young adults to elucidate the aforementioned embodiment / interoception and self-other distinction mechanisms that contribute to individual differences, such as individuals suffering from depersonalisation, alexithymia, eating disorders, and schizophrenia. Mirror touch synaesthetes present one atypical group that has been studied extensively. Here, there is growing evidence linking conscious vicarious perception with altered self-other processing. For instance, alterations in self-other perception (e.g., sense of agency and body ownership - Aimola-Davies and White, 2013; Cioffi et al., 2016; Maister et al., 2013) and the ability to control self-other representations (specifically, difficulties in controlling self-other representation in conditions that require the ability to inhibit other people; Santiesteban et al., 2015b). These findings are consistent with work suggesting that interactions between mechanisms involved in mirroring other people's experiences and self-other representation (e.g., self-other control) play a key role in vicarious perception (e.g., Bird and Viding, 2014; De Guzman et al., 2016; Lamm et al., 2016). Collectively they point to the notion that the interplay between self-other and mirroring processes may manifest themselves as individual differences in vicarious touch.

While a number of important steps have been made in understanding normative mechanisms of vicarious tactile perception, less work has focussed on individual variation and development. Altogether, developmental studies suggest that common neural mechanisms support both infant and adult processing of body-related multisensory and sensorimotor stimuli, and that these mechanisms deteriorate in older age, but very little work has directly investigated vicarious tactile representations. Future research on tactile mirroring needs to include infants, children and older adults, and examination of a range of vicarious experiences (e.g., conscious vicarious response; unconscious vicarious response; reduced vicarious response). This will permit the ability to map out developmental trajectories, and 
garner a more holistic understanding of mechanisms contributing to vicarious perception as well as of factors contributing to individual variations in these.

\section{Acknowledgements}

MJB is supported by the ESRC [ES/K00882X/1].

\section{References}

Addabbo, M., Longhi, E., Bolognini, N., Senna, I., Tagliabue, P., Cassia, V. M., \& Turati, C. (2015). Seeing touches early in life. PloS one, 10(9), e0134549.Adler, J., Schabinger, N., Michal, M., Beutel, M. E., and Gillmeister, H. (2016). Is that me in the mirror? Depersonalisation modulates tactile mirroring mechanisms, Neuropsychologia 85, 148158.

Adolphs, R., Damasio, H., Tranel, D., Cooper, G., and Damasio, A. R. (2000). A role for somatosensory cortices in the visual recognition of emotion as revealed by threedimensional lesion mapping, J. Neurosci. 20, 2683-2690.

Aimola Davies, A. M., and White, R. C. (2013). A sensational illusion: Vision-touch synaesthesia and the rubber hand paradigm, Cortex 49, 806-818.

Allison, T., McCarthy, G., Wood, C. C., Williamson, P. D., and Spencer, D. D. (1989). Human cortical potentials evoked by stimulation of the median nerve. Cytoarchitectonic areas generating long-latency activity, J. Neurophysiol. 62, 711-722.

Allison, T., McCarthy, G., and Wood, C. C. (1992). The relationship between human longlatency somatosensory evoked potentials recorded from the cortical surface and from the scalp. Electroencephalogr. Clin. Neurophysiol. 84, 301-314. 
Aspell, J. E., Palluel, E., \& Blanke, O. (2012). Early and late activity in somatosensory cortex reflects changes in bodily self-consciousness: an evoked potential study. Neuroscience, 216, 110-122.

Atkinson, J., and Braddick, O. (1982) Sensory and perceptual capacities of the neonate, in: Psychobiology of the Human Newborn, P. M. Stratton (Ed.), pp. 191-220, Wiley, London, UK.

Avenanti, A., Bueti, D., Galati, G., and Aglioti, S.M. (2005). Transcranial magnetic stimulation highlights the sensorimotor side of empathy for pain, Nat. Neurosci. 8, $955-960$.

Avikainen, S., Forss, N., and Hari, R. (2002). Modulated activation of the human SI and SII cortices during observation of hand actions, Neuroimage 15, 640-646.

Bach, P., Fenton-Adams, W., and Tipper, S. P. (2014). Can't touch this: The first-person perspective provides privileged access to predictions of sensory action outcomes, $J$. Exp. Psychol. Hum. Percept. Perform. 40(2), 457.

Bagby, R. M., Parker, J. D. A., and Taylor, G. J. (1994). The twenty-item Toronto Alexithymia Scale-I. Item selection and cross-validation of the factor structure, $J$. Psychosom. Res. 38, 23-32.

Bailey, P. E., Henry, J. D., and Von Hippel, W. (2008). Empathy and social functioning in late adulthood, Aging Ment. Health 12, 499-503.

Banissy, M. J., and Ward, J. (2007). Mirror-touch synaesthesia is linked with empathy, Nat. Neurosci. 10, 815-816.

Banissy, M. J., and Ward, J. (2013). Mechanisms of self-other representations and vicarious experiences of touch in mirror-touch synaesthesia, Front. Hum. Neurosci. 7, 112. doi: 10.3389/fnhum.2013.00112 
Banissy, M. J., Cohen Kadosh, R., Maus, G. W., Walsh, V., and Ward, J. (2009a). Prevalence, characteristics, and a neurocognitive model of mirror-touch synaesthesia, Exp. Brain Res. 198, 261-272.

Baron-Cohen, S., and Wheelwright, S. (2004). The Empathy Quotient: An investigation of adults with Asperger's syndrome or high functioning autism, and normal sex differences, J. Autism Dev. Disord. 34, 163-175.

Bernhardt, J. (1987). Sensory capabilities of the fetus. MCN Am J Matern Child Nurs. 12, $44-47$.

Bird, G. and Viding, E. (2014). The self to other model of empathy: Providing a new framework for understanding empathy impairments in psychopathy, autism, and alexithymia, Neurosci. Biobehav. Rev. 47, $520^{\circ} 32$.

Bird, G., Silani, G., Brindley, R., White, S., Frith, U., and Singer, T. (2010). Empathic brain responses in insula are modulated by levels of alexithymia but not autism, Brain 133, $1515-1525$.

Björnsdotter, M., and Olausson, H. (2011). Vicarious responses to social touch in posterior insular cortex are tuned to pleasant caressing speeds, J. Neurosci. 31, 9554-9562.

Blakemore, S. J., Bristow, D., Bird, G., Frith, C., and Ward, J. (2005). Somatosensory activations during the observation of touch and a case of vision-touch synaesthesia, Brain 128, 1571-1583.

Blanke, O., Slater, M., and Serino, A. (2015). Behavioral, neural, and computational principles of bodily self-consciousness, Neuron 88, 145-166.

Boccia, M. L. (1986). Grooming site preferences as a form of tactile communication and their role in the social relations of rhesus monkeys. In: Taub, D.M., King, F.A. (Eds.), Current Perspectives in Primate Social Dynamics. Van Nostrand Reinhold, New York, pp. 505-518. 
Bolognini, N., and Maravita, A. (2007). Proprioceptive alignment of visual and somatosensory maps in the posterior parietal cortex, Curr. Biol. 17, 1890-1895.

Bolognini, N., Rossetti, A., Maravita, A., and Miniussi, C. (2011). Seeing touch in the somatosensory cortex: A TMS study of the visual perception of touch, Hum. Brain Mapp. 32, 2104-2114.

Bolognini, N., Miniussi, C., Gallo, S., and Vallar, G. (2013a). Induction of mirror-touch synaesthesia by increasing somatosensory cortical excitability, Curr. Biol. 23, 436-437.

Bolognini, N., Rossetti, A., Convento, S., and Vallar, G. (2013b). Understanding others' feelings: The role of the right primary somatosensory cortex in encoding the affective valence of others' touch, J. Neurosci. 33, 4201-4205.

Bolognini, N., Rossetti, A., Fusaro, M., Vallar, G., and Miniussi, C. (2014). Sharing social touch in the primary somatosensory cortex, Curr. Biol. 24, 1513-1517.

Botvinick, M., and Cohen, J. (1998). Rubber hands 'feel' touch that eyes see, Nature 391(6669), 756-756.

Brass, M., Ruby, P., and Spengler, S. (2009). Inhibition of imitative behaviour and social cognition, Phil. Trans. R. Soc. Lond. B Biol. Sci. 364(1528), 2359-2367.

Bufalari, I., and Ionta, S. (2013). The social and personality neuroscience of empathy for pain and touch, Front. Hum. Neurosci. 7, 393. doi: 10.3389/fnhum.2013.00393

Bufalari, I., Aprile, T., Avenanti, A., Di Russo, F., and Aglioti, S. M. (2007). Empathy for pain and touch in the human somatosensory cortex Cereb. Cortex 17, 2553-2561.

Cardini, F., Costantini, M., Galati, G., Romani, G. L., Làdavas, E., and Serino, A. (2011). Viewing one's own face being touched modulates tactile perception: An fMRI study, $J$. Cogn. Neurosci. 23, 503-513. 
Cardini, F., Tajadura-Jiménez, A., Serino, A., and Tsakiris, M. (2013). It feels like it's me: Interpersonal multisensory stimulation enhances visual remapping of touch from other to self, J. Exp. Psychol. Hum. Percept. Perform. 39, 630-637.

Chan, A. W. Y., and Baker, C. I. (2015). Seeing is not feeling: Posterior parietal but not somatosensory cortex engagement during touch observation, J. Neurosci. 35, 14681480.

Cioffi, M. C., Banissy, M. J., and Moore, J. W. (2016). 'Am I moving?' An illusion of agency and ownership in mirror-touch synaesthesia, Cognition 146, 426-430.

Coelho Jr, A. M., Turner, S. A., and Bramblett, C. A. (1983). Allogrooming and social status: An assessment of the contributions of female behavior to the social organization of hamadryas baboons (Papio hamadryas), Primates 24, 184-197.

Coll, M. P., Bird, G., Catmur, C., \& Press, C. (2015). Cross-modal repetition effects in the mu rhythm indicate tactile mirroring during action observation. Cortex, 63, 121-131. Critchley, H. D., Wiens, S., Rotshtein, P., Öhman, A., and Dolan, R. J. (2004). Neural systems supporting interoceptive awareness, Nat. Neurosci. 7, 189-195.

Davis, M. H. (1983). Measuring individual differences in empathy: Evidence for a multidimensional approach, J. Pers. Soc. Psychol. 44, 113-126.

De Guzman, M., Bird, G., Banissy, M. J., and Catmur, C. (2016). Self-other control processes in social cognition: from imitation to empathy, Phil. Trans. R. Soc. B Biol. Sci., 371(1686), 20150079. doi: 10.1098/rstb.2015.0079

Deschrijver, E., Wiersema, J. R., and Brass, M. (2015). The interaction between felt touch and tactile consequences of observed actions: An action-based somatosensory congruency paradigm. Soc. Cogn. Affect. Neurosci. 11, 1162-1172 .

Doherty, R. W. (1997). The emotional contagion scale: A measure of individual differences, J. Nonverb. Behav. 21, 131-154. 
Ebisch, S. J., Perrucci, M. G., Ferretti, A., Del Gratta, C., Romani, G. L., and Gallese, V. (2008). The sense of touch: Embodied simulation in a visuotactile mirroring mechanism for observed animate or inanimate touch, J. Cogn. Neurosci. 20, 16111623.

Ebisch, S. J., Ferri, F., Salone, A., Perrucci, M. G., D'Amico, L., Ferro, F. M., ... and Gallese, V. (2011). Differential involvement of somatosensory and interoceptive cortices during the observation of affective touch, J. Cogn. Neurosci. 23, 1808-1822.

Elbert, T., Pantev, C., Wienbruch, C., Rockstroh, B., and Taub, E. (1995). Increased cortical representation of the fingers of the left hand in string players, Science, 270(5234), 305307.

Ernst, J., Northoff, G., Böker, H., Seifritz, E., and Grimm, S. (2013). Interoceptive awareness enhances neural activity during empathy, Hum. Brain Mapp. 34, 1615-1624.

Eshkevari, E., Rieger, E., Longo, M. R., Haggard, P., and Treasure, J. (2012). Increased plasticity of the bodily self in eating disorders, Psychol. Med. 42, 819-828.

Filippetti, M. L., Johnson, M. H., Lloyd-Fox, S., Dragovic, D., and Farroni, T. (2013). Body perception in newborns, Curr. Biol. 23, 2413-2416.

Filippetti, M. L., Lloyd-Fox, S., Longo, M. R., Farroni, T., and Johnson, M. H. (2014). Neural mechanisms of body awareness in infants, Cereb. Cortex 25, 3779-3787 .

Filippetti, M. L., Orioli, G., Johnson, M. H., and Farroni, T. (2015). Newborn body perception: sensitivity to spatial congruenc, Infancy 20, 455-465.

Fini, C., Cardini, F., Tajadura-Jiménez, A., Serino, A., and Tsakiris, M. (2013). Embodying an outgroup: the role of racial bias and the effect of multisensory processing in somatosensory remapping, Front. Behav. Neurosci. 7, 165 . doi: 10.3389/fnbeh.2013.00165 
Gallace, A., and Spence, C. (2010). The science of interpersonal touch: an overview. Neuroscience \& Biobehavioral Reviews, 34(2), 246-259. Gallese, V., and Sinigaglia, C. (2010). The bodily self as power for action, Neuropsychologia 48, 746755.

Gazzola, V., Aziz-Zadeh, L., and Keysers, C. (2006). Empathy and the somatotopic auditory mirror system in humans, Curr. Biol. 16, 1824-1829.

Gillmeister, H. (2014). A new perceptual paradigm to investigate the visual remapping of others' tactile sensations onto one's own body shows "mirror touch" for the hands, Fr. Psychol. 5, 95. doi: 10.3389/fpsyg.2014.00095.

Godde, B., Stauffenberg, B., Spengler, F., and Dinse, H. R. (2000). Tactile coactivationinduced changes in spatial discrimination performance, J. Neurosci. 20 1597-1604.

Heydrich, L., and Blanke, O. (2013). Distinct illusory own-body perceptions caused by damage to posterior insula and extrastriate cortex, Brain, 136, 790-803.

Heyes, C. (2014). Submentalizing: I am not really reading your mind, Perspect. Psychol. Sci. 9, 131-143.

Hogeveen, J., Obhi, S.S., Banissy, M.J., Santiesteban, I., Press, C., Catmur, C. and Bird, G. (2015). Task-dependent and distinct roles of the temporoparietal junction and inferior frontal cortex in the control of imitation, Soc. Cogn. Affect. Neurosci. 10, 1003-1009.

Holle, H., Banissy, M. J., Wright, T., Bowling, N., and Ward, J. (2011). “That's not a real body": Identifying stimulus qualities that modulate synaesthetic experiences of touch, Consc. Cogn. 20, 720-726.

Holle, H., Banissy, M. J., and Ward, J. (2013). Functional and structural brain differences associated with mirror-touch synaesthesia, Neuroimage 83, 1041-1050. 
Hrbek, A., Karlberg, P., and Olsson, T. (1973). Development of visual and somatosensory evoked responses in pre-term newborn infants,Electroencephalogr. Clin. Neurophysiol. 34, 225-232.

Hunter, E. C., Sierra, M., and David, A. S. (2004). The epidemiology of depersonalisation and derealisation, Soc. Psychiat. Psychiat. Epidemiol. 39, 9-18.

Ishida, H., Nakajima, K., Inase, M., and Murata, A. (2010). Shared mapping of own and others' bodies in visuotactile bimodal area of monkey parietal cortex, J. Cogn. Neurosci. 22, 83-96.

Kalisch, T., Ragert, P., Schwenkreis, P., Dinse, H. R., and Tegenthoff, M. (2009). Impaired tactile acuity in old age is accompanied by enlarged hand representations in somatosensory cortex, Cereb. Cortex 19, 1530-1538.

Kanayama, N., Sato, A., and Ohira, H. (2009). The role of gamma band oscillations and synchrony on rubber hand illusion and crossmodal integration, Brain Cogn. 69, 19-29.

Keysers, C., and Gazzola, V. (2009). Expanding the mirror: Vicarious activity for actions, emotions, and sensations, Curr. Opin. Neurobiol. 19, 666-671.

Keysers, C., Wicker, B., Gazzola, V., Anton, J. L., Fogassi, L., and Gallese, V. (2004). A touching sight: SII/PV activation during the observation and experience of touch, Neuron 42, 335-346.

Keysers, C., Kaas, J. H., and Gazzola, V. (2010). Somatosensation in social perception, Nat. Rev. Neurosci. 11, 417-428.

Kress, I. U., Minati, L., Ferraro, S., and Critchley, H. D. (2011). Direct skin-to-skin vs. indirect touch modulates neural responses to stroking vs. tapping, Neuroreport 22, 646651.

Kuehn, E., Trampel, R., Mueller, K., Turner, R., and Schütz-Bosbach, S. (2013). Judging roughness by sight — A 7-tesla fMRI study on responsivity of the primary 
somatosensory cortex during observed touch of self and others, Hum. Brain Mapp. 34, $1882-1895$.

Kuehn, E., Mueller, K., Turner, R., and Schütz-Bosbach, S. (2014). The functional architecture of S1 during touch observation described with 7 T fMRI, Brain Struct. Funct. 219, 119-140.

Kuehn, E., Mueller, K., Lohmann, G., and Schuetz-Bosbach, S. (2016). Interoceptive awareness changes the posterior insula functional connectivity profile, Brain Struct. Funct. 221, 1555-1571.

Lamm, C., Decety, J., and Singer, T. (2011). Meta-analytic evidence for common and distinct neural networks associated with directly experienced pain and empathy for pain, Neuroimage 54, 2492-2502.

Lamm, C., Silani, G., and Singer, T. (2015). Distinct neural networks underlying empathy for pleasant and unpleasant touch, Cortex 70, 79-89.

Lamm, C., Bukowski, H., and Silani, G. (2016). From shared to distinct self-other representations in empathy: Evidence from neurotypical function and socio-cognitive disorders, Phil. Trans. R. Soc. B 371(1686), 20150083. doi: 10.1098/rstb.2015.0083

Lane, R.D., Sechrest L., and Riedel, R. (1998). Sociodemographic correlates of alexithymia, Compr. Psychiat. 39, 377-385.

Lankinen, K., Smeds, E., Tikka, P., Pihko, E., Hari, R., and Koskinen, M. (2016). Haptic contents of a movie dynamically engage the spectator's sensorimotor cortex, Hum. Brain Mapp. 37, 4061-4068.

Legrand, D. (2006). The bodily self: The sensori-motor roots of pre-reflective selfconsciousness, Phenomenol. Cogn. Sci. 5, 89-118. 
Light, K. C., Grewen, K. M., and Amico, J. A. (2005). More frequent partner hugs and higher oxytocin levels are linked to lower blood pressure and heart rate in premenopausal women, Biol. Psychol. 69, 5-21.

Lockwood, P. L. (2016). The anatomy of empathy: Vicarious experience and disorders of social cognition, Behav. Brain Res. 311, 255-266.

Mahayana, I. T., Banissy, M. J., Chen, C. Y., Walsh, V., Juan, C. H., and Muggleton, N. G. (2014). Motor empathy is a consequence of misattribution of sensory information in observers, Front. Hum. Neurosci. 8, 47. doi: 10.3389/fnhum.2014.00047

Maister, L., Banissy, M. J., and Tsakiris, M. (2013). Mirror-touch synaesthesia changes representations of self-identity, Neuropsychologia 51, 802-808.

Marshall, P. J., and Meltzoff, A. N. (2014). Neural mirroring mechanisms and imitation in human infants. Phil. Trans. R. Soc. B, 369(1644), 20130620.

Marshall, P. J., Saby, J. N., and Meltzoff, A. N. (2013). Imitation and the developing social brain: Infants somatotopic EEG patterns for acts of self and other, Int. J. Psychol. Res. (Medellin) 6, 22-29.

Martinez-Jauand, M., Gonzalez-Roldan, A. M., Munoz, M. A., Sitges, C., Cifre, I., and Montoya, P. (2012). Somatosensory activity modulation during observation of other's pain and touch, Brain Res. 1467, 48-55.

Mattila, A. K., Salminen, J. K., Nummi, T., and Joukamaa, M. (2006). Age is strongly associated with alexithymia in the general population, J. Psychosom. Res. 61, 629-635.

Mehling, W. E., Price, C., Daubenmier, J. J., Acree, M., Bartmess, E., and Stewart, A. (2012). The multidimensional assessment of interoceptive awareness (MAIA), PLoS One, 7, e48230. doi: 10.1371/journal.pone.0048230 
Meyer, K., Kaplan, J. T., Essex, R., Damasio, H., and Damasio, A. (2011). Seeing touch is correlated with content-specific activity in primary somatosensory cortex, Cereb. Cortex 21, 2113-2121. doi: 10.1093/cercor/bhq289.

Molenberghs, P., Cunnington, R., and Mattingley, J. B. (2012). Brain regions with mirror properties: a meta-analysis of 125 human fMRI studies, Neurosci. Biobehav. Rev. 36, $341-349$.

Molnar-Szakacs, I., and Uddin, L. Q. (2013). Self-processing and the default mode network: interactions with the mirror neuron system, Front. Hum. Neurosci. 7, 571. doi: 10.3389/fnhum.2013.00571

Mooradian, T. A., Davis, M., \& Matzler, K. (2011). Dispositional empathy and the hierarchical structure of personality. The American journal of psychology, 124(1), 99109.

Mussap, A. J., and Salton, N. (2006). A 'rubber-hand'illusion reveals a relationship between perceptual body image and unhealthy body change, J. Health Psychol. 11, 627-639

Nummenmaa, L., Smirnov, D., Lahnakoski, J. M., Glerean, E., Jääskeläinen, I. P., Sams, M., and Hari, R. (2014). Mental action simulation synchronizes action-observation circuits across individuals, J. Neurosci. 34, 748-757.

Otsuru, N., Hashizume, A., Nakamura, D., Endo, Y., Inui, K., Kakigi, R., and Yuge, L. (2014). Sensory incongruence leading to hand disownership modulates somatosensory cortical processing, Cortex 58, 1-8.

Paradiso, S., Vaidya, J. G., McCormick, L. M., Jones, A., and Robinson, R. G. (2008). Aging and alexithymia: association with reduced right rostral cingulate volume, Am. J. Ger. Psychiat. 16, 760-769.

Pascual-Leone, A., and Torres, F. (1993). Plasticity of the sensorimotor cortex representation of the reading finger in Braille readers Brain 116, 39-52. 
Pihko, E., Nangini, C., Jousmäki, V., and Hari, R. (2010). Observing touch activates human primary somatosensory cortex, Eur. J. Neurosci. 31, 1836-1843.

Pineda, J. A. (2005). The functional significance of mu rhythms: translating "seeing" and "hearing” into “doing”, Brain Res. Rev. 50, 57-68.

Ragert, P., Schmidt, A., Altenmüller, E., and Dinse, H. R. (2004). Superior tactile performance and learning in professional pianists: evidence for meta-plasticity in musicians, Eur. J. Neurosci. 19, 473-478.

Remijn, G. B., Kikuchi, M., Shitamichi, K., Ueno, S., Yoshimura, Y., Nagao, K., Tsubokawa, T., Kojima. H., Higashida, H., and Minabe, Y. (2014). Somatosensory evoked field in response to visuotactile stimulation in 3-to 4-year-old children, Front. Hum. Neurosci. 8, 170. doi: 10.3389/fnhum.2014.00170.

Rigato, S., Ali, J. B., van Velzen, J., and Bremner, A. J. (2014). The neural basis of somatosensory remapping develops in human infancy, Curr. Biol. 24, 1222-1226.

Rizzolatti, G. and Craighero, L. (2004). The mirror-neuron system, Annu. Rev. Neurosci. 27, $169-192$.

Rochat, P., and Striano, T. (2000). Perceived self in infancy, Infant Behav. Dev. 23, 513-530.

Rossetti, A., Miniussi, C., Maravita, A., and Bolognini, N. (2012). Visual perception of bodily interactions in the primary somatosensory cortex, Eur. J. Neurosci. 36, 23172323.

Ruby, P., and Decety, J. (2001). Effect of subjective perspective taking during simulation of action: a PET investigation of agency, Nat. Neurosci. 4, 546-550.

Ruffman, T., Henry, J. D., Livingstone, V., and Phillips, L. H. (2008). A meta-analytic review of emotion recognition and aging: Implications for neuropsychological models of aging, Neurosci. Biobehav. Rev. 32, 863-881. 
Rutherford, M. D. (2004). The effect of social role on theory of mind reasoning. British Journal of Psychology, 95(1), 91-103.

Saby, J. N., Meltzoff, A. N., and Marshall, P. J. (2013). Infants' somatotopic neural responses to seeing human actions: I've got you under my skin, PLoS One 8, e77905. doi: 10.1371/journal.pone.0077905

Saby, J. N., Meltzoff, A. N., and Marshall, P. J. (2015). Neural body maps in human infants: Somatotopic responses to tactile stimulation in 7-month-olds, Neuroimage 118, 74-78.

Santiesteban, I., Banissy, M.J., Catmur, C. and Bird, G. (2012). Enhancing social ability by stimulating right temporoparietal junction, Curr. Biol. 22, 2274-2277.

Santiesteban, I., Bird, G., Tew, O., Cioffi, M.C. and Banissy, M.J. (2015a). Mirror-touch synaesthesia: Difficulties inhibiting the other, Cortex 71, 116-121.

Santiesteban, I., Shah, P., White, S., Bird, G., and Heyes, C. (2015b). Mentalizing or submentalizing in a communication task? Evidence from autism and a camera control, Psychon. Bull. Rev. 22, 844-849.

Schaefer, M., Flor, H., Heinze, H. J., and Rotte, M. (2006). Dynamic modulation of the primary somatosensory cortex during seeing and feeling a touched hand, Neuroimage 29, 587-592.

Schaefer, M., Xu, B., Flor, H., and Cohen, L. G. (2009). Effects of different viewing perspectives on somatosensory activations during observation of touch, Hum. Brain Mapp. 30, 2722-2730.

Schaefer, M., Heinze, H. J., and Rotte, M. (2012). Embodied empathy for tactile events: interindividual differences and vicarious somatosensory responses during touch observation, Neuroimage 60, 952-957. 
Schaefer, M., Rotte, M., Heinze, H. J., and Denke, C. (2013). Mirror-like brain responses to observed touch and personality dimensions, Front. Hum. Neurosci. 7, 227. doi: 10.3389/fnhum.2013.00227

Schubert, R., Ritter, P., Wustenberg, T., Preuschhof, C., Curio, G., Sommer, W., et al. (2008). Spatial attention related SEP amplitude modulations covary with BOLD signal in S1 - A simultaneous EEG-fMRI study, Cereb. Cortex 18, 2686-2700.

Serino, A., Pizzoferrato, F., and Làdavas, E. (2008). Viewing a face especially one's own face being touched enhances tactile perception on the face, Psychol. Sci. 19, 434-438.

Serino, A., Giovagnoli, G., and Làdavas, E. (2009). I feel what you feel if you are similar to me, Plos One, 4(3), e4930. doi: 10.1371/journal.pone.0004930

Sierra, M., Lopera, F., Lambert, M. V., Phillips, M. L., and David, A. S. (2002). Separating depersonalisation and derealisation: the relevance of the "lesion method", J. Neurol. Neurosurg. Psychiat. 72, 530-532.

Simeon, D. (2004). Depersonalisation disorder: A contemporary overview, CNS Drugs 18, $343-354$.

Simeon, D., Giesbrecht, T., Knutelska, M., Smith, R. J., and Smith, L. M. (2009). Alexithymia, absorption, and cognitive failures in depersonalization disorder: A comparison to posttraumatic stress disorder and healthy volunteers, J. Nerv. Ment. Dis. 197, 492-498.

Singer, T., Seymour, B., O’Doherty, J., Kaube, H., Dolan, R.J., and Frith, C.D. (2004). Empathy for pain involves the affective but not sensory components of pain, Science 303, 1157-1162.

Spengler, F., Godde, B., and Dinse, H. R. (1995). Effects of ageing on topographic organization of somatosensory cortex, Neuroreport 6, 469-473. 
Streltsova, A., and McCleery, J. P. (2014). Neural time-course of the observation of human and non-human object touch, Soc. Cogn. Affect. Neurosci. 9, 333-341.

Tamir, D. I., and Mitchell, J. P. (2010). Neural correlates of anchoring-and-adjustment during mentalizing, Proc. Natl Acad. Sci. 107, 10827-10832.

Taylor, M. J., Boor, R., and Ekert, P. G. (1996). Preterm maturation of the somatosensory evoked potential, Electroencephalogr. Clin. Neurophysiol. 100, 448-452.

Thakkar, K. N., Nichols, H. S., McIntosh, L. G., and Park, S. (2011). Disturbances in body ownership in schizophrenia: Evidence from the rubber hand illusion and case study of a spontaneous out-of-body experience, PloS One 6, e27089. doi: 10.1371/journal.pone.0027089

Tsakiris, M. (2008). Looking for myself: current multisensory input alters self-face recognition, PloS One 3, e4040. doi: 10.1371/journal.pone.0004040

Tsakiris, M., Tajadura-Jiménez, A., and Costantini, M. (2011). Just a heartbeat away from one's body: Interoceptive sensitivity predicts malleability of body-representations. Proc. R. Soc. Lond. B Biol. Sci. 278(1717), 2470-2476.

Vandenbroucke, S., Crombez, G., Loeys, T., and Goubert, L. (2015). Vicarious experiences and detection accuracy while observing pain and touch: The effect of perspective taking, Atten. Percept. Psychophys. 77, 1781-1793.

Ward, J., and Banissy, M. J. (2015). Explaining mirror-touch synaesthesia, Cogn. Neurosci. 6, 118-147.

White, R. C., and Davies, A. M. A. (2012). Specular vision-touch synaesthesia: Two reference frames, Perception 41, 871-874.

Wood, R., Gallese, V., and Cattaneo, L. (2010). Visuotactile empathy within the primary somatosensory cortex revealed by short-latency afferent inhibition, Neuroscience Lett. $473,28-31$. 
Wood, A., Rychlowska, M., Korb, S., and Niedenthal, P. (2016). Fashioning the face: sensorimotor simulation contributes to facial expression recognition, Trends Cogn. Sci. 20, 227-240.

Yang, T., \& Banissy, M.J. (2016). Empathy and aging: Mechanisms of empathy throughout adulthood. In Psychology and Neurobiology of Empathy, Edited by D.F. Watt and J. Panksepp. Nova.

Zmyj, N., Jank, J., Schutz-Bosbach, S., and Daum, M. M. (2011). Detection of visual-tactile contingency in the first year after birth, Cognition 120, 82-89. 